\title{
RESPONSE PROCESSING DURING VISUAL SEARCH IN NORMAL AGING: THE NEED FOR MORE TIME TO PREVENT CROSS TALK BETWEEN SPATIAL ATTENTION AND MANUAL RESPONSE SELECTION
}

Authors: Elena Amenedo ${ }^{\mathrm{a} *}$, Laura Lorenzo-Lopez ${ }^{\mathrm{b}}$, Paula Pazo-Alvarez ${ }^{\mathrm{a}}$.

This is the peer reviewed version of the following article: Amenedo E., Lorenzo-López L., PazoÁlvarez P. (2012). Response processing during visual search in normal aging: The need for more time to prevent cross talk between spatial attention and manual response selection. Biological Psychology, 91: 201-211. doi: 10.1016/j.biopsycho.2012.06.004

This article may be used for non-commercial purposes in accordance with Elsevier and conditions for use of self-archived versions. 
Response processing during visual search in normal aging: the need for more time to prevent cross talk between spatial attention and manual response selection

Authors: Elena Amenedo ${ }^{\mathrm{a}_{*}}$, Laura Lorenzo-Lopez ${ }^{\mathrm{b}}$, Paula Pazo-Alvarez ${ }^{\mathrm{a}}$.

${ }^{a}$ Department of Clinical Psychology and Psychobiology, Faculty of Psychology, University of Santiago de Compostela, Spain

${ }^{b}$ Gerontology Research Group, Department of Medicine, Faculty of Health Sciences, University of A Coruña, Spain

* Corresponding author at: Campus Sur S/N, 15782, Santiago de Compostela, Galicia, Spain. Tel.: +34 981563 100x13916; fax: +34 981528 071. E-mail address: elena.amenedo@usc.es (E. Amenedo). 


\begin{abstract}
It is still not well known whether the age-related behavioural slowing observed during visual search is due to changes in the allocation of attention, in response activation patterns, or to a combination of both. To help in clarifying it, attention-related (N2 posterior contralateral; N2pc, and N2 central contralateral; N2cc) and response-related (Motor Potential; MP, and Reafferent Potential; RAP) event-related potentials (ERPs) were obtained in healthy young and older participants executing a visual search task. Age was associated with N2pc and N2cc longer latencies, earlier MP onsets and longer MP rise times. Lower N2pc, higher MP and lower RAP amplitudes were also observed. Results suggest that older participants need more time to allocate spatial attention onto the target $(\mathrm{N} 2 \mathrm{pc})$ and to prevent cross talk between response selection and attention direction $(\mathrm{N} 2 \mathrm{cc})$, and that they are slower and need higher cortical activation when preparing and executing correctly selected responses (MP).
\end{abstract}




\section{Introduction}

The visual search paradigm has been extensively used in laboratory studies to examine the basic properties of human visual selective attention (Luck and Ford, 1998; Luck and Hillyard, 1994a,b). In this paradigm, participants search for a predefined target stimulus that is randomly presented in arrays containing a variable number of bilateral distractor stimuli. In a typical single feature visual search task, like that employed in the present study, the target differs from distractors in a physical attribute (i.e. orientation change), and the participants are required to indicate whether the target is present or absent in each array of stimuli by pressing a pre-assigned response button.

Previous electrophysiological studies of visual search in young humans have revealed a posterior negative-going ERP component that appears contralateral to the visual hemifield in which the target is located 200-300 ms after the onset of a bilateral stimulus array (Eimer, 1996; Luck and Hillyard, 1994a,b; Woodman and Luck, 1999). This component was first described as the N2pc (N2-posterior-contralateral) to indicate its polarity, latency range, and scalp distribution (Luck and Hillyard, 1994a), and it has been well-validated as an electrophysiological correlate of the focusing of visuospatial attention onto a target stimulus during visual search (Eimer, 1996; Luck and Hillyard, 1994a,b; Luck and Ford, 1998; Luck et al., 1997; Woodman and Luck, 1999, 2003). The N2pc is recorded with maximum amplitude over parietal-occipital electrode sites contralateral to the attended item (Eimer, 1996; Luck and Hillyard, 1994a,b), and it is primarily generated in lateral occipital-temporal regions (Hopf et al., 2000; Lorenzo-Lopez et al., 2011).

There is considerable evidence that older adults are behaviourally slower in tasks involving visual search (Hommel et al., 2004; Madden and Whiting, 2004; McDowd and Shaw, 2000). However, several questions remain unsolved regarding the interpretation of these findings. Mainly, it is still not well established if they represent a slowing related to deficiencies in the allocation of attention onto the target, to deficient response activation patterns, or to a combination of them. During the period between the onset of the target in the visual field and the emission of a correct response, several processes related to both attention and motor mechanisms take place. Specifically, allocation of attention onto the target and motor selection and preparation processes both contribute to the reaction time (RT) recorded during the execution of the task, and any or both of them may be affected by age.

Recent studies have helped in solving the first of the above questions by providing the first evidence that normal aging significantly affects the allocation of visuospatial attention itself during single feature visual search (N2pc component, Lorenzo-Lopez et al., 2008a) by delaying the time needed to allocate spatial attention shifts onto the target and reducing the attention resources deployed to it. More recently, these age-related changes in N2pc parameters have been associated with a significant hypoactivation of its occipital-temporal neural sources that is more marked in the right hemisphere (Lorenzo-López et al., 2011). However, it is still not possible to conclude whether the age-related behavioural changes observed during visual search tasks are also due to changes in the processes related to the selection and preparation of motor responses to the correct detection of the target.

In recent years, an ERP component related to the prevention of cross talk between attention direction and manual response selection has been described (Oostenveld et al., 2001; Praamstra,

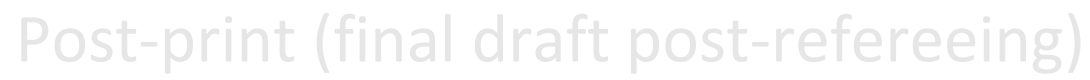


2006; Praamstra and Oostenveld, 2003). This component, named N2cc (N2 central-contralateral) is recorded at central electrodes contralateral to the side of presentation of the target stimuli during visuospatial attention tasks, and it presents the same polarity and latency as the above-described $\mathrm{N} 2 \mathrm{pc}$ component. Based on results from single cell recordings on non-human primates (Crammond and Kalaska, 2000; Shen and Alexander, 1997; Wise et al., 1996, 1997), from neuroimaging data (Connolly et al., 2000; Dassonville et al., 2001) and from ERP current source analyses (Praamstra, 2006; Praamstra and Oostenveld, 2003), N2cc has been proposed to reflect activation of the dorsal premotor cortex that is invoked to prevent the selection of a manual response depending on the location of the target stimulus in the visual field, and hence to ensure that the response selection is not biased by the direction of spatial attention (Praamstra and Oostenveld, 2003). More recently, the fact that this component is reduced in amplitude when advance information of target location is provided by a cue has added support to its functional interpretation (Praamstra, 2006). In visual search tasks, the target stimulus appears randomly interspersed with distractor stimuli in the right or left visual field in each trial. In these tasks, it is frequent to assign one hand to respond to the presence of the target and the other to its absence independently of its position in the visual field. Under such circumstances, responses executed with the hand ipsilateral to the visual hemifield where the target appears are facilitated. Thus the ability to select the correct response hand depending on the task instructions and not on the position of the target in the right or left visual field can be considered an executive function that helps inhibiting the vulnerability of response choice to be influenced by the direction of attention (Praamstra, 2006). In this regard, measuring the N2cc component makes it possible to explore the effects of aging on this executive function during visual search. Moreover, although the N2pc component has been well characterized in older samples (Lorenzo-López et al., 2008a, 2011), it was also examined in the present study in order to compare age-related effects on stimulus-related attention ERPs with those on response-related attention ERPs (Praamstra and Oostenveld, 2003).

The observation of slower RTs in older populations is not limited to visual search tasks, but is also present in almost every study on aging. In fact, the ubiquity of this age-related effect has lead to influential theories of cognitive aging and to classical debates in this research context (Salthouse, 1996; McDowd and Shaw, 2000). Some recent ERP evidence has indicated that cortical dysregulation in motor activation patterns may underlie response slowing with age in choice reaction tasks (Falkenstein et al., 2006; Yordanova et al., 2004), although to our knowledge the mechanisms underlying the behavioural slowing during visual search tasks have not been examined yet.

ERP research has shown that any task requiring an overt response to a stimulus activates electrocortical motor mechanisms immediately after or even in parallel with stimulus processing. Before a correct response is overtly executed, several ERP components associated to movement selection and preparation processes are generated in motor cortical areas. One of the most prominent ERPs associated with active limb movements is the Readiness Potential (RP; Deecke et al., 1969; Böcker et al., 1994; Shibasaki and Hallett, 2006). The RP develops through different components among which the most prominent for finger movements is a maximum negative deflection appearing just before the observable movement onset at contralateral central electrodes (Motor Potential, MP) followed by a positive deflection that is maximal around the overt movement execution (Reafferent Potential, RAP). The MP indexes motor generation of a selected response at contralateral motor cortex (Böcker et al., 1994). The functional significance of the

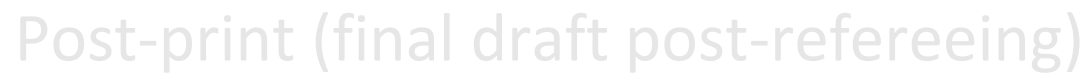


RAP, although less well known, has been related to sensorymotor integration processes during response execution (Bötzel et al., 1997; Seiss et al., 2002; Szurhaj et al., 2006). Thus, measuring the MP and the RAP components elicited during correct responses to the target stimulus in a visual search task should allow examining motor generation and sensory-motor integration processes that take place between target onset and response execution, and their age-related changes.

Finally, in order to examine the relations between the recorded response-related electrophysiological activity and the behavioural performance during the task independently of the effects of age, partial correlations (Baron and Kenny, 1986; Perry et al., 2009; Volkow et al., 1998) were computed between the N2cc and RP (MP and RAP) parameters (latency and amplitude values) and the execution data (RTs and hit rates).

\section{Methods}

\section{Participants}

The original sample consisted of 17 young (10 females, $19.6 \pm 1.9$ years, range 18-24) and 22 older adults (11 females, $68.5 \pm 6$ years, range 60-84). However, four young (all female) and five older (4 female) participants were discarded from the original sample because of excessively noisy EEG motor-related activity that led to low signal-to-noise ratios for ERP-averaging purposes. Finally, data from 13 young ( 6 females, $20.08 \pm 2.02$ years, range 18-24), and 17 older adults ( 8 females, $68.29 \pm 6.54$ years, range $60-84$ ) were tested. All participants were healthy well-functioning without a history of neurological or psychiatric disorders, had normal or corrected-to-normal visual acuity, reported normal colour vision, and were righthanded (Oldfield, 1971). None of the older participants had received a diagnosis of glaucoma or cataracts, and they performed the Mini-Mental State Examination (MMSE) (Folstein et al., 1975) showing normal scores (>28). Informed consent was obtained from all subjects and they were paid for their participation in the experiment.

\section{Stimuli and experimental procedure}

Recordings were made in an electrically shielded and sound attenuated room. Subjects sat in a comfortable armchair at $100 \mathrm{~cm}$ viewing distance from a computer screen with a black background and a continuously visible fixation white cross. They were instructed to maintain central fixation on this cross while they performed a visual search task consisting in detecting a target stimulus presented among an array of distractors that differed from them in its orientation (Fig. 1). On each trial a multi-element search array was presented composed of eight bars subtending a visual angle of $0.3 \circ \times 0.9 \circ$, which were located at random positions within an imaginary rectangle of $9.2 \circ \times 6.9^{\circ}$ of visual angle around fixation cross. There were always four bars in each visual hemifield. Three types of search arrays were randomly presented: homogeneous arrays, arrays containing a target defined by a change in orientation of one of the bars, and arrays containing a non-target defined by a change in colour of one of the bars. Homogeneous arrays $(p=.6)$ consisted of eight blue-horizontal (RGB 0, 0, 255) identical bars. Orientation target arrays $(\mathrm{p}=.2)$ consisted of seven blue-horizontal bars and one blue-vertical bar. Colour non-target arrays $(\mathrm{p}=.2)$ consisted of seven blue-horizontal bars and one redhorizontal (RGB 255, 0,0) bar. The orientation target and the colour non-target were equally likely to appear in the right or left visual hemifield and their location was unpredictable.

Each search array was presented for $750 \mathrm{~ms}$, followed by a variable inter-trial interval of 900$1100 \mathrm{~ms}$ during which only fixation cross was present. The same feature (orientation) defined the 
target across all trials and the subjects were not informed about the appearance of the colour nontarget. All the stimuli and search arrays were created, presented, and controlled using the Presentation software application (Neurobehavioral Systems, Inc., version 0.76). The experimental session was divided into six blocks of trials, and several training trials were run before testing to ensure a good level of performance in both age groups. Each block consisted of at least 10 arrays containing an orientation target and 10 arrays containing a colour non-target presented to each hemifield, and at least 80 homogeneous arrays, to a possible maximum of 250 arrays in total. Participants were required to indicate as rapidly and accurately as possible whether the orientation target (a vertical bar) was present or absent in each search array by pressing a button with one hand for target present trials and another button with the other hand for targetabsent trials. Thus, the colour non-target arrays required the same response hand as the homogeneous arrays (target-absent). Response buttons were counterbalanced across subjects. As a result, in 16 participants ( 7 young and 9 older) the right hand was assigned to respond to target present arrays and the left hand to target-absent arrays, and in 14 participants (6 young and 8 older) the left hand was assigned to target-present arrays and the right hand to target-absent arrays.

\section{ERP recordings}

The electroencephalogram (EEG) was recorded with a NeuroScan system using scalp electrocaps (ECI, Inc.) with 30 electrodes placed at FP1, FP2, FPz, Fz, Cz, Pz, POz, Oz, F7, F8, F3, F4, C3, C4, T3, T4, PO3, PO4, FCz, CPz, CP3, CP4, T5, T6, P3, P4, FC3, FC4, O1 and O2 (10/20 International System). All the active electrodes were referred to the nose tip and grounded with an electrode placed at nasion. Vertical and horizontal electrooculogram (EOG) activities were recorded bipolarly from above and below the left eye and from the outer canthi of both eyes. Electrode impedances were kept below $10 \mathrm{k}$. The EEG signals were continuously amplified (10 $\mathrm{K})$ and digitized at a rate of $500 \mathrm{~Hz} / \mathrm{channel}$, and filtered on-line with a band pass of $0.05-100$ $\mathrm{Hz}$.

\section{Data analysis}

\section{Behavioural data}

Reaction times (RTs) were on-line recorded for all subjects to the three types of search arrays in all experimental blocks (for orientation target and colour nontarget arrays, RTs to stimuli appearing in the right or left visual field were separately recorded). Only RT values associated with correct responses were considered for data analyses. Hit rates were calculated as the total percentage of correct responses with RTs no longer than $1100 \mathrm{~ms}$. A common problem with using percentages as response variables is that the distribution of proportions may "pile-up" against 0 or 1, resulting in skewed data (i.e. non-normal distributions). Additionally this may lead to unequal variances. For meeting the assumptions of ANOVA, the original hit rates were firstly converted to proportions and then arcsine root transformed (Osborne, 2002). Mean correct RTs were compared across groups using a repeated measures analysis of variance (ANOVA) with age (young, older) and response hand (right, left) as the between-subjects factors, and search array (homogeneous, orientation right left target, and colour right-left non-target) as the within-subject factor. Original and transformed hit rates were also compared across groups using ANOVAs with age (young, older) and response hand (right, left) as the between-subjects factors. An alpha level of .05 was used for all analyses.

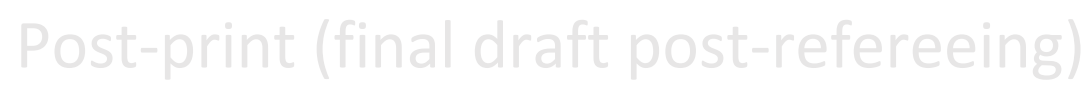




\section{EEG data}

All EEG data were off-line processed using Vision Analyzer software (Version 2.0). The EEG was digitally filtered with a $0.1-30 \mathrm{~Hz}$ band pass filter. Filtered EEG was segmented in epochs of $900 \mathrm{~ms}$ post-stimulus and $100 \mathrm{~ms}$ pre-stimulus to obtain attention-related ERPs (N2pc and $\mathrm{N} 2 \mathrm{cc}$, see below), and in epochs of $1000 \mathrm{~ms}$ post response and $1000 \mathrm{~ms}$ pre-response for the motor-related RP components (MP and RAP, see below). In all segmentation files, epochs exceeding $\pm 100 \mathrm{~V}$ and those containing blinks, and horizontal or vertical eye movements were rejected and excluded from averaging, as well as epochs associated with incorrect or no responses. Because in previous research by our group no differential ERP effects related to attentional focusing were observed to colour non-target stimuli (Lorenzo-López et al., 2008a), only EEG segments associated with correct responses to orientation target stimuli were averaged for both attention ERPs (N2pc and N2cc) and motor ERPs (RP). Separate averages were obtained to orientation targets appearing in the right visual field (RVF) and to those appearing in the left visual field (LVF). This resulted in 4 attention-related and 2 response-related waveforms for each participant (see below).

2.1. Attention-related ERP data: N2pc and N2cc components. For the derivation of the N2pc component, difference waveforms for each participant were obtained by subtracting ipsilateral from contralateral ERPs relative to the target location in the right or the left visual field at posterior electrodes PO3 and PO4 respectively (see Lorenzo-López et al., 2008a,b). For the derivation of the N2cc component, difference waveforms for each participant were obtained by subtracting ipsilateral from contralateral ERPs relative to the visual field of attention following Praamstra (2006) formula that reads N2cc $=[(\mathrm{C} 3-\mathrm{C} 4) \mathrm{RVF}$ attention $+(\mathrm{C} 4+\mathrm{C} 3) \mathrm{LVF}$ attention $] / 2$, where 'RVF' refers to the right visual field, and 'LVF' to the left visual field. This procedure extracts lateralized potentials collapsing the activity of both hemispheres (see Praamstra, 2006). In the resulting waveforms of both $\mathrm{N} 2 \mathrm{pc}$ and $\mathrm{N} 2 \mathrm{cc}$ components, mean amplitude values were obtained from 150 to $300 \mathrm{~ms}$ for the young adults, and from 200 to $450 \mathrm{~ms}$ for the older adults (these latency intervals were selected as the most representative for each group after visual inspection of the respective grand mean waveforms, see Figs. 2 and 3, and Lorenzo-López et al., 2008a,b). In order to test the effects of age on N2pc and N2cc parameters, peak amplitude, mean amplitude, and latency values of these components were entered into separate ANOVAs. For N2pc values, mixed ANOVAs with age (young, older) as the between-subjects factor and electrode (PO3, PO4) as the within-subject factor were run. For N2cc values, one-way ANOVAs with age (young, older) as the between-subjects factor were executed. An alpha level of .05 was used.

2.2. Response-related ERP data: MP and RAP components. RP averages to orientation targets were analysed at relevant electrodes at the contralateral motor areas ( $\mathrm{C} 3$ for right hand responders, and $\mathrm{C} 4$ for left hand responders). Baseline was defined in these ERPs as a $200 \mathrm{~ms}$ interval between 1000 and $800 \mathrm{~ms}$ before the motor response (button press). Peak latency and amplitude values of the most negative displacement of the RP, the MP, were measured within the interval between stimulus presentation and response execution. Peak latency and amplitude values were also measured for the most positive displacement of the RP, the RAP, after the MP. The onset latency of the MP was calculated as the time when MP amplitude was $15 \%$ of its maximal value (cf. Mordkoff and Gianaros, 2000; Schwarzenau et al., 1998). The duration of the MP activation (MP rise time) was measured as the difference between MP peak latency and MP onset latency.

MP and RAP peak latency and amplitude values, and MP onset and rise time values were submitted to separate repeated measures ANOVAs with age (young, older) and response hand 
(right, left) as the between-subjects factors, and target-response compatibility (compatible targetresponse side, incompatible target-response side) as the within-subject factor. An alpha level of .05 was used for all statistical tests. Whenever appropriate, degrees of freedom were corrected by the conservative Greenhouse-Geisser estimate. When necessary, post hoc comparisons were performed using the Bonferroni adjustment for multiple comparisons.

2.3. ERP-behaviour analyses. To examine the relationships between behavioural execution and electrophysiological activity independently of the effects of age, partial correlation analyses controlling for age (Baron and Kenny, 1986; Perry et al., 2009; Volkow et al., 1998) were executed between both RT and hit rates, and the latency and amplitude values measured for N2cc, MP and RAP components. Because no differences between RTs to right and left targets, and no interactions between response hand, age or array type were observed (see results), the mean RT values to both target stimuli were employed to compute partial correlations between N2cc and RT. In the case of motor components (MP and RAP) the amplitude and latency values obtained to compatible target stimuli were used for the correlation analyses. Partial correlations were considered significant at $\mathrm{p}<.05$ (two-tailed).

\section{Results}

\section{Behavioural results}

As can be appreciated in Table 1, the RTs were significantly slower in the older group for each array type $\left(\mathrm{F}(1,26)=33.69, \mathrm{p}<.0001, n_{\mathrm{p}}^{2}=.56\right)$ irrespective of the hand assigned to respond to the targets $\left(\mathrm{F}(1,26)=.38, \mathrm{p}=.54 n_{\mathrm{p}}^{2}=.01\right)$. The effect of the array type was also significant on mean RTs $\left(\mathrm{F}(4,104)=29.29, \mathrm{p}<.0001, \varepsilon=.43, n_{\mathrm{p}}^{2}=.53\right)$ showing the longest response times for orientation targets, intermediate for colour non-targets, and the shortest RTs for the homogeneous arrays (see Table 1). No statistically significant interactions were observed between age and response hand $\left(\mathrm{F}(1,26)=3.11, \mathrm{p}=.09, n_{\mathrm{p}}^{2}=.11\right)$, between age and array type $(\mathrm{F}(4,104)=.58$, $\left.\mathrm{p}=.54, n_{\mathrm{p}}^{2}=.02\right)$ or between response hand and array type $\left(\mathrm{F}(4,104)=.80, \mathrm{p}=.44,=n_{\mathrm{p} .03}^{2}\right)$. Moreover, target-response compatibility effects were not significant on RT values $(\mathrm{F}(1,28)=.61$, $\mathrm{p}=.44, n_{\mathrm{p}}^{2}=.02$ ) in either young (target-response compatible: $500.55 \pm 51.61 \mathrm{~ms}$, incompatible: $500.50 \pm 49.97 \mathrm{~ms}$ ) or older participants (target-response compatible: $595.72 \pm 55.61 \mathrm{~ms}$, incompatible: $604.34 \pm 42.07 \mathrm{~ms})$. Effects of age $\left(\mathrm{F}(1,26)=3.77, \mathrm{p}=.06, n_{\mathrm{p}}^{2}=.13\right)$ or response hand $\left(\mathrm{F}(1,26)=.16, \mathrm{p}=.70, n_{\mathrm{p}}^{2}=.006\right)$ were not statistically significant on hit rates (young right hand: $97.58 \pm 2.68 \%$, left hand: $98.55 \pm .36$; older right hand: $96.51 \pm 3.23 \%$, left hand: $94.50 \pm$ $5.40 \%)$. No significant interactions between age and response hand were observed $(\mathrm{F}(1,26)=$ $1.28, \mathrm{p}=.27 n_{\mathrm{p}}^{2}=.05$ ). The results of the ANOVA executed on the arcsine root transformed data revealed significant effects of age that indicated worse performance levels in the older participants $\left(\mathrm{F}(1,26)=4.73, \mathrm{p}<.04 n_{\mathrm{p}}^{2}=.15\right)$. No significant effects of the response hand $(\mathrm{F}(1,26)=.15, \mathrm{p}=$ $\left..70 n_{\mathrm{p}}^{2}=.006\right)$ or of the interaction between age and response hand $\left(\mathrm{F}(1,26)=1.26, \mathrm{p}=.27, n_{\mathrm{p}}^{2}\right.$ $=.05$ ) were observed on these transformed data.

\section{Electrophysiological results}

\section{Attention-related ERPs: N2pc and N2cc components}

Significant effects of age were observed on both N2pc (Figs. 2 and 4) and N2cc (Figs. 3 and 4) peak latencies $\left(\mathrm{N} 2 \mathrm{pc}: \mathrm{F}(1,28)=37.69, \mathrm{p}<.0001 n_{\mathrm{p}}^{2}=.69 ; \mathrm{N} 2 \mathrm{cc}: \mathrm{F}(1,28)=16.56, \mathrm{p}<.0001, n_{\mathrm{p}}^{2}\right.$ 
$=.49$ ) indicating longer values in the older group (see Table 2). N2pc peak amplitude $(\mathrm{F}(1,28)=$ $\left.5.6, \mathrm{p}<.02, n_{\mathrm{p}}^{2}=.17\right)$ and mean amplitude $\left(\mathrm{F}(1,28)=4.67, \mathrm{p}<.04 n_{\mathrm{p}}^{2}=.32\right)$ were significantly lower in the older participants, whereas $\mathrm{N} 2 \mathrm{cc}$ peak amplitude $\left(\mathrm{F}(1,28)=.05, \mathrm{p}=.82, n_{\mathrm{p}}^{2}=.06\right)$ and mean amplitude $\left(\mathrm{F}(1,28)=.57, \mathrm{p}=.46, n_{\mathrm{p}}^{2}=.01\right)$ were not affected by age, although they showed a slight trend to higher values in the older group (see Table 2 and Fig. 3).

\section{Response-related motor ERP: MP and RAP components}

The results on the motor MP component showed higher peak amplitudes, earlier onset latencies and longer durations in the older participants independently of the hand assigned to respond to the target, and to target-response compatibility effects. Specifically, the older participants showed significantly higher amplitudes of the MP component $\left(\mathrm{F}(1,26)=4.15, \mathrm{p}<.05, n_{\mathrm{p}}^{2}=.15\right)$ than the young participants (Table 3 and Fig. 5). MP amplitudes were significantly higher in targetresponse compatible trials $\left(\mathrm{F}(1,26)=5.16, \mathrm{p}<.03, n_{\mathrm{p}}^{2}=.17\right)$ irrespective of the hand assigned to respond to the orientation target $\left(\mathrm{F}(1,26)=.97, \mathrm{p}=.34, n^{2}{ }_{\mathrm{p}}=.04\right)$. No significant interactions were observed on this parameter ('age by response hand': $\mathrm{F}(1,26)=1.37, \mathrm{p}=.25, n_{\mathrm{p}}{ }^{2}=.05$; 'target-response compatibility by age': $\mathrm{F}(1,26)=.81, \mathrm{p}=.38, n_{\mathrm{p}}^{2}=.03$; 'target-response compatibility by response hand': $\left.\mathrm{F}(1,26)=.64, \mathrm{p}=.43, n^{2}{ }_{\mathrm{p}}=.02\right)$. Similar values of MP peak latency were observed for both young and older participants $\left(\mathrm{F}(1,26)=.03, \mathrm{p}=.87, n_{\mathrm{p}}^{2}=.001\right)$. The spatial compatibility between target location and response hand had no significant effects on peak latency values of the MP $\left(\mathrm{F}(1,26)=.28, \mathrm{p}=.60, n_{\mathrm{p}}^{2}=.01\right)$. However, the hand assigned to respond influenced the results $\left(\mathrm{F}(1,26)=4.57, \mathrm{p}<.04, n_{\mathrm{p}}^{2}=.15\right)$ indicating that MP peaked slightly earlier in participants who responded to the target with their right hand (see Table 3 , and Fig. 5). Again, no significant interactions between age and response hand $(\mathrm{F}(1,26)=.35, \mathrm{p}=.87$, $2 \mathrm{p}=.01)$, age and target-response compatibility $\left(\mathrm{F}(1,26)=.64, \mathrm{p}=.43, n_{\mathrm{p}}^{2}=.02\right)$ or response hand and target-response compatibility $\left(\mathrm{F}(1,26)=.77, \mathrm{p}=.39, n_{\mathrm{p}}^{2}=.03\right)$ were found. MP onset showed significant differences $\left(\mathrm{F}(1,26)=16.84, \mathrm{p}<.0001, n_{\mathrm{p}}^{2}=.39\right)$ between young and older participants indicating that in the older participants the MP began earlier (Table 3). Targetresponse compatibility effects were significant in both age groups $(F(1,26)=42.12, p<.0001$, $2 p=62$ ), and no differences as a function of the hand employed to respond to the target were observed in any age group on this parameter $\left(\mathrm{F}(1,26)=.50, \mathrm{p}=.48, n_{\mathrm{p}}^{2}=.02\right)$. Specifically, irrespective of the hand assigned to respond, MP started earlier for target-response incompatible trials than for target-response compatible trials in all participants ('target-response compatibility by age' $\left.\mathrm{F}(1,26)=.47, \mathrm{p}=.50, n_{\mathrm{p}}^{2}=.02\right)$ indicating the need for more time to prepare the correct response when target appeared in the location opposite to the response hand. No interactions were found between age and response hand $\left(\mathrm{F}(1,26)=.04, \mathrm{p}=.84, n^{2}{ }_{\mathrm{p}}=.002\right)$ or between response hand and target-response compatibility $\left(\mathrm{F}(1,26)=.79, \mathrm{p}=.38, n_{\mathrm{p}}^{2}=.03\right)$. MP rise time was also significantly affected by age $\left(\mathrm{F}(1,26)=18.94, \mathrm{p}<.0001, n^{2}{ }_{\mathrm{p}}=.42\right)$ showing longer duration for the older compared to the young participants (Table 3, and Fig. 5) irrespective of the hand assigned to respond to the target $\left(\mathrm{F}(1,26)=.47, \mathrm{p}=.50, n_{\mathrm{p}}^{2}=.02\right)$. Moreover, MP rise times were shorter when targets appeared in the visual field compatible with the response side $(F(1,26)=$ $27.73, \mathrm{p}<.0001, n_{\mathrm{p}}^{2}=.52$ ) in all participants ('target-response compatibility by age' $\mathrm{F}(1,27)=$ $.06, \mathrm{p}=.81, n_{\mathrm{p}}^{2}=.002$ ) and irrespective of the response hand ('target-response compatibility by response hand' $\mathrm{F}(1,26)=3.10, \mathrm{p}=.09, n_{\mathrm{p}}^{2}=.11$; 'age by response hand' $\mathrm{F}(1,26)=.71, \mathrm{p}=.41$, $2 \mathrm{p}=.03$ ). The RAP component showed effects of both age and response hand on its amplitude. Specifically, RAP amplitudes $\left(\mathrm{F}(1,26)=32.78, \mathrm{p}<.0001, n_{\mathrm{p}}^{2}=.56\right)$ were significantly lower in the older than in the young group (Table 3 and Fig. 5). Moreover, RAP amplitudes differed in all participants as a function of the hand used to respond to the target $\left(\mathrm{F}(1,26)=5.56, \mathrm{p}<.03 n_{\mathrm{p}}^{2}=\right.$ .18) showing slightly larger amplitudes for participants using their right hand (Table 3 ). 
Targetresponse compatibility effects were not observed on the amplitude of this component $\left(\mathrm{F}(1,26)=.03, \mathrm{p}=.86, n_{\mathrm{p}}^{2}=.001\right)$, and no interactions were observed ('age by response hand' $\mathrm{F}(1,26)=.18, \mathrm{p}=.68, n_{\mathrm{p}}{ }^{2}=.007$; 'age by target-response compatibility' $\mathrm{F}(1,26)=.29, \mathrm{p}=.59 n_{\mathrm{p}}^{2}$ $=.01$; 'response hand by target-response compatibility' $\left.\mathrm{F}(1,26)=2.67, \mathrm{p}=.11, n_{\mathrm{p}}^{2}=.09\right)$. Finally, no significant effects of age $\left(\mathrm{F}(1,26)=3.41, \mathrm{p}=.08, n_{\mathrm{p}}^{2}=.12\right)$, response hand $(\mathrm{F}(1,26)=.94$, $\left.\mathrm{p}=.34, n_{\mathrm{p}}^{2}=.03\right)$ or target-response compatibility $\left(\mathrm{F}(1,26)=.49, \mathrm{p}=.49, n_{\mathrm{p}}^{2}=.02\right)$ were observed on the latency of the RAP component, and no interactions between any of the

factors were found ('age by response hand' $\mathrm{F}(1,26)=.002, \mathrm{p}=.97, n_{\mathrm{p}}^{2}=.00$; 'age by targetresponse compatibility' $\mathrm{F}(1,26)=.79, \mathrm{p}=.38, n_{\mathrm{p}}^{2}=.03$; 'response hand by target-response compatibility' $\left.\mathrm{F}(1,26)=.92, \mathrm{p}=.34, n_{\mathrm{p}}^{2}=.03\right)$.

\section{ERP-behaviour relationships}

Partial correlation analyses showed that, once the effects of age were taken into account significant relationships emerged between behavioural (RT and hit rates) and response-related electrophysiological (N2cc, MP and RAP) measures (Table 4). Specifically, RT was positively correlated to N2cc peak latency, N2cc peak amplitude and MP peak amplitude, and negatively correlated to N2cc mean amplitude. On the other hand, hit rate was negatively correlated to MP and RAP peak latencies, and MP rise time (Table 4). Regarding RT-N2cc correlations, these results indicated that longer RT values were associated with longer N2cc latencies, higher N2cc peak amplitudes, and lower N2cc mean amplitudes. The correlation between RT and MP peak amplitude showed that slower responses to targets were associated with higher amplitudes of the MP. Finally, partial correlations indicated that higher hit rates were related to earlier MP latencies and shorter MP rise times, and to earlier RAP peak latencies (Table 4).

\section{Discussion}

In the present study, stimulus and response-related ERPs were recorded while healthy young and older adults searched for a singleton feature target defined by an orientation change relative to bilateral surrounding distractor stimuli. The main objective was to complement previous research on age-related changes in visual search (Lorenzo-López et al., 2008a, 2011) by examining the possibility that electrocortical activity related to motor and sensory-motor processing is contributing to the slowing of behavioural response observed in visual search tasks. Specifically, to address age-related changes in attention-related ERPs associated with the prevention of manual responses determined by the direction of attention the N2cc component was examined (see Praamstra, 2006). To address movement preparation and execution-related ERP activity, the MP and RAP components of the RP were analysed (Shibasaki and Hallett, 2006). Moreover, the possible relationships between the above referred electrocortical activity and behavioural performance (RT and hit rate) were also examined independently of the effects of age.

\section{Behavioural results}

Behavioural results revealed an age-related delay in RTs, which is in line with those of our previous (Lorenzo-López et al., 2008a, 2011) and other behavioural studies showing that older participants are slower than young participants in tasks involving visual search (Hommel et al., 2004; Madden and Whiting, 2004; McDowd and Shaw, 2000). There was an effect of age on hit rates once the original data were arcsine root transformed. This result, according to previous studies (Hommel et al., 2004; Lorenzo-López et al., 2008a,b, 2011; Madden and Whiting, 2004; McDowd and Shaw, 2000), indicates that older adults executed the search task at lower accuracy levels than young participants. 


\section{Electrophysiological results}

The electrophysiological results on the attention-related components showed that age was significantly associated with longer latencies of both N2pc and N2cc. Moreover, in agreement with previous results (Lorenzo-López et al., 2008a) lower peak amplitudes and mean amplitudes of $\mathrm{N} 2 \mathrm{pc}$ were also observed in the elderly group of the present study. $\mathrm{N} 2 \mathrm{cc}$ amplitude values, although showing a slight trend to be higher in the older participants, were not significantly affected by age. Regarding the results on the motor ERPs, the older participants showed higher amplitudes, earlier onsets and longer rise times of MP, along with lower amplitudes of RAP. Moreover, these effects of age on MP and RAP components were independent of the hand assigned to respond to the target, and of target-response compatibility effects.

\subsection{Attention-related ERPs: N2pc and N2cc components:}

In visual spatial attention tasks, correctly detected targets appearing at lateral locations elicit two contralateral negative deflections at the same latencies, one that is recorded over parietaloccipital electrodes (the N2pc, Luck and Ford, 1998; Luck and Hillyard, 1994a,b) and another that is recorded over central electrodes (the N2cc, Oostenveld et al., 2001; Praamstra and Plat, 2001). The N2pc is a well-established electrophysiological index of the deployment of visuospatial shifts of attention onto the location of a target stimulus that is generated in extrastriate occipitaltemporal cortical areas (Hopf et al., 2004; Lorenzo-López et al., 2011). The proper inhibition of incorrect responses based on the location of the target is needed, which would promote dorsal premotor cortex activation and N2cc generation (see Praamstra, 2006).

\subsection{Response-related motor ERPs: MP and RAP components:}

The results on the motor MP component showed higher peak amplitudes, earlier onset latencies and longer durations in the older participants independently of the hand assigned to respond to the target, and to target-response compatibility effects. The MP is generated in the contralateral primary motor cortex, and it is related to the preparation and initiation of the motor command resulting in an overt response (Böcker et al., 1994; Deecke et al., 1969; Shibasaki and Hallett, 2006). Previous reports on motor ERPs have showed higher age-related amplitudes of this component in choice reaction tasks (Falkenstein et al., 2006; Yordanova et al., 2004), and studies employing fMRI have found additional age-related activation in the contralateral motor cortical areas during the performance of simple movements (Mattay et al., 2002; Ward and Frackowiak, 2003) and in areas associated to suppression of preeminent response tendencies and inhibitory cognitive control both during simple and complex movements (Heuninckx et al., 2005).

According to the above reports, the age-related changes observed in the amplitude, onset latency and rise time of the MP component in this study indicate that older adults need higher, earlier and longer activation of the contralateral motor cortex to prepare and execute correctly selected responses to the targets during the visual search task, thus complementing the scarce existing data on response-related brain activity on aging.

A new finding in the present study was that age also affected the amplitude of the RAP component that was markedly reduced in the older participants independently of the hand employed to respond and to the target-response compatibility effects. Toour knowledge, this is the first study having tested age-related changes in this motor component. The origins and functional 
significance of this component are still not well known although recent reports have shown evidence of a relationship between RAP and sensory-motor integration during movement execution. Specifically, more classical studies had suggested that the RAP was related to postmovement reafferent sensory-motor processes generated in somatosensory cortical areas (Bötzel et al., 1997; Shibasaki et al., 1980). This interpretation, however, received little support (for a review see Shibasaki and Hallett, 2006) until recent years when studies employing intracortical recordings in humans found clear relationships between RAP amplitude and gamma event-related synchronization (ERS) in the 40-60 Hz band at contralateral sensorimotor cortices (Szurhaj et al., 2005, 2006). Initial descriptions of gamma band oscillations related them to multiple sensory and cognitive processes, but recent studies associate $40-60 \mathrm{~Hz}$ rhythms in sensorimotor cortical regions with the somesthetic reafferentation from the muscles and joints necessary for controlling the ongoing movement (see Szurhaj and Derambure, 2006). Szurhaj et al. (2005) interpreted the relationship between the amplitude of RAP component and gamma ERS as indicating that this component is functionally related to the facilitation of afferences from muscles and joints involved in the movement to the motor cortico-spinal cells, necessary for controlling the ongoing movement (Szurhaj et al., 2005, 2006). The lower RAP amplitudes observed in the older group of the present study would therefore suggest a deficient sensory-motor integration and hence a poorer control of movement during the execution of the correct responses in the visual search task.

\subsection{Target-response compatibility effects}

Stimulus-response compatibility has been extensively studied. In general, it consists in a shortening of RTs when target stimulus and response are spatially compatible (Hommel, 1993). Even when the spatial location of the target stimulus is irrelevant to the task this effect is clearly seen. Simon and Rudell (1967) described this special compatibility effect with auditory stimulation, and since then it has been called Simon effect. In the present study the relevant feature to the task was target orientation, therefore the compatibility effects here can be attributed to a Simon-like effect.

We observed similar RTs in all participants for both target-response compatible and incompatible trials. Moreover, no interactions with age or response hand were observed. The absence of Simonlike effects on RTs in the present study may probably be related to the fact that only one hand was assigned to respond to both right and left targets, reducing the choice component that matches the spatial dimensions of stimulus and response and resulting in similar RTs for both compatible and incompatible trials. In this sense, the Simon effect is normally reduced when the task demands blur the match between the spatial dimensions of stimulus and response (Hommel, 1993; JuncosRabadán et al., 2008). Moreover, the lack of age-related differences in compatibility effects may be associated with the stimulus configuration in the present task. In this sense, it has been found that when tasks include irrelevant, spatially varying secondary stimuli accompanying the relevant stimulus (as in the visual search task used in the present study) there are no effects of age on stimulus-response compatibility effects on RTs (Proctor et al., 2005a,b).

Although no effects of target-response compatibility were observed on the RT values, the MP component showed significant modulations as a function of spatial target-response compatibility independently of age and response hand. When target and response were spatially incompatible (left target-right response and vice versa) MP showed lower amplitude, it began earlier and 
consequently its duration was longer indicating lower and slower electrocortical activation in contralateral motor areas to prepare and execute the correct response in this trials. This result partially agrees with previous reports on stimulus-response compatibility effects observed on lateralized motor ERPs obtained by averaging the contralateral minus the ipsilateral electrocortical activity for the responses executed with both hands (the Lateralized Readiness Potential, LRP, see Coles et al., 1988). In general, in stimulus-response incompatible trials lower amplitudes of the LRPare observed that have been traditionally explained as the result of the automatic initiation of electrocortical activity at the ipsilateral but incorrect hemisphere (see Gratton et al., 1988). The compatibility effects observed on the MP motor component were independent of the age of participants and of the hand assigned to respond to the targets. To our knowledge, only a previous study has explored age related changes in the Simon effect on motor ERPs. In this study, Van der Lube and Verleger (2002) obtained the LRP during the execution of a visual Simon Task in young and older adults and they did not find effects of age on this ERP component. Although in the present study it was not possible to obtain the LRP as only one hand was assigned to the target presence in the visual field, our results are in line with the absence of age-related differences in the compatibility effects on the LRP observed previously by these authors (Van der Lube and Verleger, 2002).

\subsection{Hand assignment effects}

The hand assigned to respond to the target showed significant effects only on MP peak latency and on RAP amplitude, which peaked earlier and presented higher amplitude respectively when participants were assigned the right hand to detect the presence of the target in the visual field. This result, probably related to the handedness of the participants (all right-handed; see Knösche et al., 1996; Kutas and Donchin, 1974) may indicate facilitated motor preparation and sensorymotor integration during response execution when movements were performed with the dominant hand (Knösche et al., 1996). However, there were no significant interactions between response hand and age or target-response compatibility, therefore indicating that earlier MP latencies and larger RAP amplitudes were present in both young and older participants responding with their right hand to all targets (independently of they appearing in the left or in the right visual field).

\section{Response ERPs-behaviour relationships}

The results of partial correlation analyses indicated that, independently of age, longer RT values were associated with longer N2cc latencies, higher N2cc peak amplitudes, and lower N2cc mean amplitudes. Moreover, the correlations between RT and MP peak amplitudes showed that slower responses to targets were associated with higher amplitudes of the MP. Finally, partial correlations indicated that higher hit rates were related to earlier MP latencies and shorter MP rise times, and to earlier RAP peak latencies. In general, the significant correlations observed between RTs and response-related ERPs help in explaining the significant age-related effects observed on the response-related components analysed in the present study. Firstly, the association 'slower N2cc - slower RT' makes the explanation given for the age-related longer RTs and later N2cc latencies observed in the present study more feasible since it indicates that slower behavioural responses are related to the need for more time to prevent the selection of responses determined by the location of the target stimulus in the visual field during a single feature visual search task. Secondly, the correlations between RT and N2cc amplitudes indicate that in general those participants responding with slower RTs presented higher and more phasic activation in dorsal 
premotor areas to successfully inhibit incorrect responses when targets appeared in the same side than the response hand, which would add partial support to the slight trend to higher N2cc amplitudes observed in the older group. Thirdly, the association 'slower RTs - higher MP amplitudes' gives support to the explanation of age-related behavioural slowing as partly due to higher motor cortical activation during the preparation of the selected correct responses (Falkenstein et al., 2006; Yordanova et al., 2004).

\section{Conclusions}

The results of the present study complement our previous findings on the electrophysiological patterns that underlie the age related behavioural slowing observed in visual search tasks by showing that slower responses to correctly detected targets in these tasks are also due to (a) slower activation in dorsolateral premotor cortex to inhibit incorrect responses promoted by the target location when selecting the correct ones determined by task instructions, (b) higher and longer activation patterns in motor areas when preparing the correctly selected responses, and (c) poorer sensory-motor mapping during the execution of the correct responses during the task. Moreover, the conjoint examination of attention-related ERP components associated to stimulus (N2pc) and response ( $\mathrm{N} 2 \mathrm{cc}$ ) during the visual search task gives support to a possible age-related increased direct visuomotor transmission from posterior to anterior brain areas that would decrease inhibitory control of incorrect responses.

\section{Disclosure statement}

There are no actual or potential conflicts of interest that could inappropriately influence this work. Informed consent was obtained from all participants in the experiment and their rights were protected.

\section{Acknowledgements}

This study was supported by grants from the Spanish MICINN (PSI2010-21427) and Xunta de Galicia (10PXIB211220PR). 


\section{References}

Baron, R.M., Kenny, D.A., 1986. The moderator-mediator variable distinction in social psychological research: conceptual, strategic, and statistical considerations. Journal of Personality and Social Psychology 51, 1173-1182.

Bocker, K.B.E., Brunia, C.H.M., Cluitman, P.J.M., 1994. A spatio-temporal dipole model of the readiness potential in humans. I. Finger movement. Electroencephalography and Clinical Neurophysiology 91, 275-285.

Botzel, K., Ecker, C., Schulze, S., 1997. Topography and dipole analysis of reafferent electrical brain activity following the Bereitschaftspotential. Experimental Brain Research 114, 352-361.

Coles, M.G.H., Gratton, G., Donchin, E., 1988. Detecting early communication: using measures of movement-related potentials to illuminate human information processing. Biological Psychology 26, 69-89.

Connolly, J.D., Goodale, M.A., Desouza, J.F.X., Menon, R.S., Vilis, T., 2000. A comparison of frontoparietal fMRI activation during anti-saccades and anti-pointing. Journal of Neurophysiology 84, 1645-1655.

Crammond, D.J., Kalaska, J.F., 2000. Prior information in motor and premotor cortex: activity during the delay period and effect on pre-movement activity. Journal of Neurophysiology 84, 986-1005.

Dassonville, P., Lewis, S.M., Zhu, X.H., Ugurbil, K., Kim, S.G., Ashe, J., 2001. The effect of stimulusresponse compatibility on cortical motor activation. NeuroImage 13, 1-14.

Deecke, L., Scheid, P., Kornhuber, H.H., 1969. Distribution of readiness potential, promotion positivity, and motor potential of the human cerebral cortex preceeding voluntary finger movements. Experimental Brain Research 7, 158-168.

Eimer, M., 1996. The N2pc component as an indicator of attentional selectivity. Electroencephalography and Clinical Neurophysiology 99, 225-234.

Falkenstein, M., Yordanova, J., Kolev, V., 2006. Effects of aging on slowing of motorresponse generation. International Journal of Psychophysiology 59, 22-29.

Folstein, M.F., Folstein, S.E., McHugh, P.R., 1975. Mini-mental state. A practical method for grading the cognitive state of patients for the clinician. Journal of Psychiatric Research 12 (3), 189-198.

Gratton, G., Coles, M.G.H., Sirevaag, E.J., Eriksen, C.W., Donchin, E., 1988. Pre- and post-stimulus activation of response channels: a psychophysiological analysis. Journal of Experimental Psychology: Human Perception and Performance 14, 331-344.

Heuninckx, S., Wenderoth, N., Debaere, F., Peeters, R., Swinnen, S.P., 2005. Neural basis of aging: the penetration of cognition into action control. The Journal of Neuroscience 25, 6787-6796.

Hommel, B., 1993. The relationship between stimulus processing and response selection in the Simon task: evidence for a temporal overlap. Psychological Research 55, 280-290.

Hommel, B., Li, K.Z., Li, S.C., 2004. Visual search across the life span. Developmental Psychology 40 (4), 458-545.

Hopf, J.M., Luck, S.J., Girelli, M., Hagner, T., Mangun, G.R., Scheich, H., Heinze, H.J., 2000. Neural sources of focused attention in visual search. Cerebral Cortex 10, 1233-1241.

Hopf, J.M., Boelmans, K., Schoenfeld, A.M., Luck, S.J., Heinze, H.J., 2004. Attention to features precedes attention to locations in visual search: evidence from electromagnetic brain responses in humans. Journal of Neuroscience 24 (8), 1822-1832.

Juncos-Rabadan, O., Pereiro, A.X., Facal, D., 2008. Cognitive interference and aging: insights from a spatial stimulus-response consistency task. Acta Psychologica 127, 237-246. 
Knosche, T., Praamstra, P., Stegeman, D., Peters, M., 1996. Linear estimation discriminatesmidline sources and a motor cortex contribution to the readiness potential. Electroencephalography and clinical Neurophysiology 99, 183-190.

Kutas, M., Donchin, E., 1974. Studies of squeezing: handedness, responding hand, response force, and asymmetry of readiness potential. Science $186,545-548$.

Lorenzo-Lopez, L., Amenedo, E., Cadaveira, F., 2008a. Feature processing during visual search in normal aging: electrophysiological evidence. Neurobiology of Aging 29, 1101-1110.

Lorenzo-Lopez, L., Amenedo, E., Pascual-Marqui, R.D., Cadaveira, F., 2008b. Neural correlates of agerelated visual search decline: a combined ERP and sLORETA study. NeuroImage 41, 511-524.

Lorenzo-Lopez, L., Gutierrez, R., Moratti, S., Maestu, F., Cadaveira, F., Amenedo, E., 2011. Age-related occipito-temporal hypoactivation during visual search: relationships between $\mathrm{mN} 2 \mathrm{pc}$ sources and performance. Neuropsychologia 49, 858-865.

Luck, S.J., Ford, M.A., 1998. On the role of selective attention in visual perception. Proceedings of the National Academy of Sciences of United States of America 95 (3), 825-830.

Luck, S.J., Hillyard, S.A., 1994a. Spatial filtering during visual search: evidence from human electrophysiology. Journal of Experimental Psychology: Human Perception and Performance 20, $1000-1014$.

Luck, S.J., Hillyard, S.A., 1994b. Electrophysiological correlates of feature analysis during visual search. Psychophysiology 31 (3), 291-308.

Luck, S.J., Girelli, M., McDermott, M.T., Ford, M.A., 1997. Bridging the gap between monkey neurophysiology and human perception: an ambiguity resolution theory of visual selective attention. Cognitive Psychology 33, 64-87.

Madden, D.J., Whiting, W.L., 2004. Age-related changes in visual attention. In: Costa, P.T., Siegler, I.C. (Eds.), Recent Advances in Psychology and Aging. Elsevier, Amsterdam, pp. 41-88.

Mattay, V.S., Fera, F., Tessitore, A., Hariri, A.R., Das, S., Callicott, J.H., Weinberger, D.R., 2002. Neurophysiological correlates of age-related changes in human motor function. Neurology 58, 630-635.

McDowd, J.M., Shaw, R.J., 2000. Attention and aging: a functional perspective. In: Craik, F.I.M., Salthouse, T.A. (Eds.), The Handbook of Aging and Cognition., $2^{\text {nd }}$ ed. Lawrence Erlbaum Associates Publishers, Mahwah, NJ, US, pp. 221-292.

Miller, E.K., Cohen, J.D., 2001. An integrative theory of prefrontal cortex function. Annual Review of Neuroscience 24, 167-202.

Mordkoff, J.T., Gianaros, P.J., 2000. Detecting the onset of the lateralized readiness potential: a comparison of available methods and procedures. Psychophysiology 37, 347-360.

Oldfield, R.C., 1971. The assessment and analysis of handedness: the Edinburgh inventory. Neuropsychologia 9, 97-113.

Oostenveld, R., Praamstra, P., Stegeman, D.F., van Oosterom, A., 2001. Overlap of attention and movement-related activity in lateralized event-related brain potentials. Clinical Neurophysiology $112,477-484$.

Osborne, J., 2002. Notes on the use of data transformations. Practical Assessment. Research \& Evaluation $8,6,1-9$.

Perrin, F., Pernier, J., Bertrand, O., Echallier, J.F., 1989. Spherical splines for scalp potential and current density mapping. Electroencephalography and Clinical Neurophysiology 72, 174-187 (posterior correction in 1990 in Electroencephalography and Clinical Neurophysiology 76, 565).

Perry, M.E., McDonald, C.R., Hagler Jr., D.J., Gharapetian, L., Kuperman, J.M., Koyama,A.K., Dale, A.M., McEvoy, L.K., 2009. White matter tracts associated with setshiftingin healthy aging. Neuropsychologia 47, 2835-2842. 
Praamstra, P., 2006. Prior information of stimulus location: effects on ERP measures of visual selection and response selection. Brain Research 1072, 153-160.

Praamstra, P., Oostenveld, R., 2003. Attention and movement-related motor cortex activation: a highdensity EEG study of spatial stimulus-response compatibility. Cognitive Brain Research 16, 309322.

Praamstra, P., Plat, F.M., 2001. Failed suppression of direct visuomotor activation in Parkinson's disease. Journal of Cognitive Neuroscience 13, 31-43.

Proctor, R.W., Pick, D.F., Vu, K.L., Anderson, R.E., 2005a. The enhanced Simon effect for older adults is reduced when the irrelevant location information is conveyed by an accessory stimulus. Acta Psychologica 119, 21-40.

Proctor, R.W., Vu, K.L., Pick, D.F., 2005b. Aging and response selection in spatial choice tasks. Human Factors. The Journal of the Human Factors and Ergonomics Society 47, 250-270.

Ridderinkhof, K.R., van den Wildenberg, W.P.M., Segalowitz, S.J., Carter, C.S., 2004. Neurocognitive mechanisms of cognitive control: the role of prefrontal cortex in action selection, response inhibition, performance monitoring, and rewardbased learning. Brain and Cognition 56, 129-140.

Salthouse, T.A., 1996. The processing-speed theory of adult age differences in cognition. Psychological Review 103 (3), 403-428.

Schwarzenau, P., Falkenstein, M., Hoorman, J., Hohnsbein, J., 1998. A new method for the estimation of the onset of the lateralized readiness potential (LRP). Behavioral Research Methods, Instrumentation and Computation 30, 110-117.

Seiss, E., Hess, C.W., Drane, S., Oostenveld, R., Wing, A.M., Praamstra, P., 2002. Propioception-related evoked potentials: origin and sensitivity to movement parameters. NeuroImage 17, 461-468.

Shen, L., Alexander, G.E., 1997. Preferential representation of instructed target location versus limb trajectory in dorsal premotor area. Journal of Neurophysiology 77, 1195-1212.

Shibasaki, H., Hallett, M., 2006. What is Bereitschaftspotential? Clinical Neurophysiology 117, 23412356.

Shibasaki, H., Barrett, G., Halliday, E., Halliday, A.M., 1980. Cortical potentials following voluntary and passive finger movements. Electroencephalography and Clinical Neurophysiology 50, 201-213.

Simon, J.R., Rudell, A.P., 1967. Auditory S-R compatibility: the effect of an irrelevant cue on information processing. Journal of Applied Psychology 51, 300-304.

Szurhaj, W., Derambure, P., 2006. Intracerebral study of gamma oscillations in the human sensorimotor cortex. In: Neuper, C., Klimesch, W. (Eds.), Event-Related Dynamics of Brain Oscillations. Progress in Brain Research, vol. 159. Elsevier, Amsterdam, pp. 297-310.

Szurhaj, W., Bourriez, J.L., Kahane, P., Chauvel, P., Mauguiere, F., Derambure, P., 2005. Intracerebral study of gamma rhythm reactivity in the sensorimotor cortex. European Journal of Neuroscience 21, 1223-1235.

Szurhaj, W., Labyt, E., Bourriez, J.L., Kahane, P., Chauvel, P., Mauguiere, F., Derambure,P., 2006. Relationship between intracerebral gamma oscillations and slow potentials in the human sensorimotor cortex. European Journal of Neuroscience 24, 947-954.

Van der Lube, R.H.J., Verleger, R., 2002. Aging and the Simon task. Psychophysiology 39, 100-110.

Volkow, N.D., Gur, R.C., Wang, G.J., Fowler, J.S., Moberg, P.J., Ding, Y.S., Hitzemann, R., Smith, G., Logan, J., 1998. Association between decline in brain dopamine activity with age and cognitive and motor impairment in healthy individuals. American Journal of Psychiatry 155, 344-349.

Ward, N.S., Frackowiak, R.S.J., 2003. Age-related changes in the neural correlates of motor performance. Brain 126, 873-888.

Wise, S.P., Di Pellegrino, G., Boussaoud, D., 1996. The premotor cortex and nonstandard sensorimotor mapping. Canadian Journal of Physiology and Pharmacology 74, 469-482. 
Wise, S.P., Boussaoud, D., Johnson, P.B., Caminity, R., 1997. Premotor and parietal cortex: corticocortical connectivity and combinatorial computations. AnnualReview of Neuroscience 20, $25-42$.

Woodman, G.F., Luck, S.J., 1999. Electrophysiological measurement of rapid shifts of attention during visual search. Nature 400, 867-869.

Woodman, G.F., Luck, S.J., 2003. Serial deployment of attention during visual search. Journal of Experimental Psych: Human Perception and Performance 29, 121-138.

Yordanova, J., Kolev, V., Hohnsbein, J., Falkenstein, M., 2004. Sensorimotor slowing with ageing is mediated by a functional dysregulation of motor-generation processes: evidence form highresolution event-related potentials. Brain 127, 351-362. 
$750 \mathrm{~ms}$

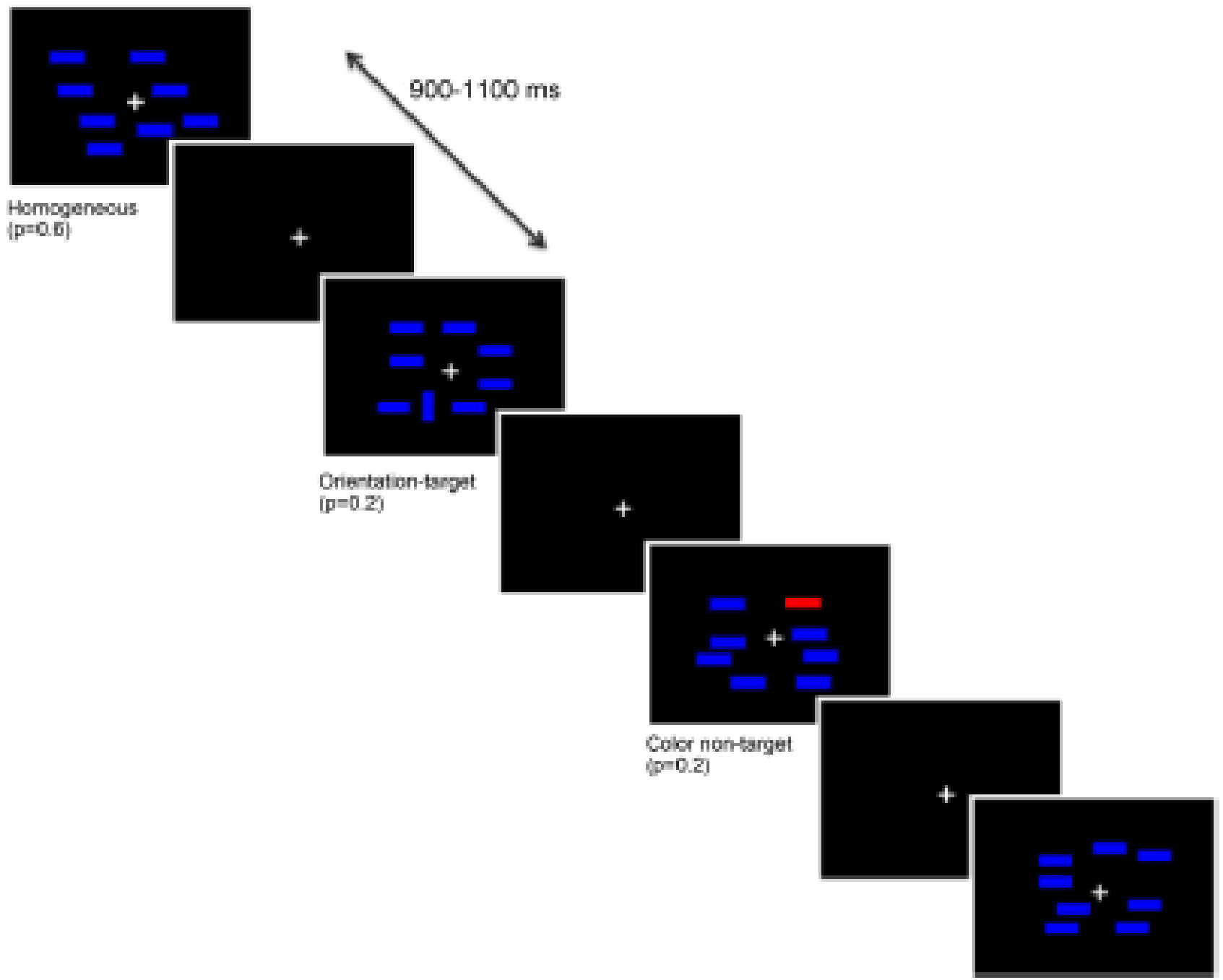

Fig. L. Graphic desription of task properties 


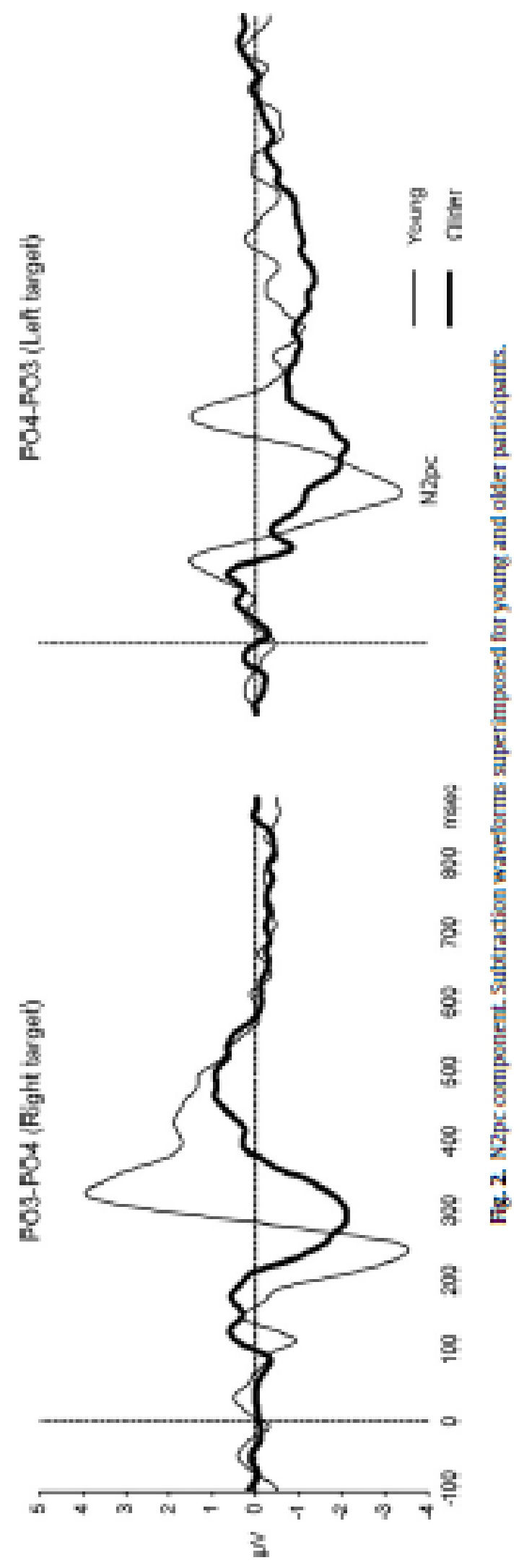

Post-print (final draft post-refereeing) 
Table I

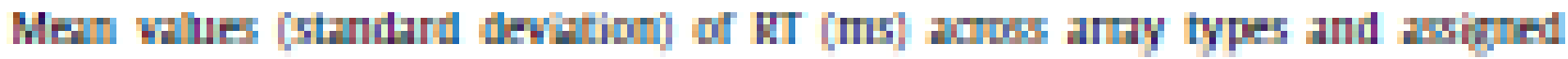
repponse hand in each age poup.

\begin{tabular}{|c|c|c|c|c|c|}
\hline & Hompgnews & $\begin{array}{l}\text { Colour } \\
\text { right }\end{array}$ & $\begin{array}{l}\text { Conour } \\
\text { leit }\end{array}$ & $\begin{array}{l}\text { Target } \\
\text { right }\end{array}$ & $\begin{array}{l}\text { Target } \\
\text { left }\end{array}$ \\
\hline \multicolumn{6}{|c|}{ Right tand } \\
\hline Young & $\begin{array}{l}\text { 45486 } \\
{[051]}\end{array}$ & $\begin{array}{l}46210 \\
77.37\end{array}$ & $\begin{array}{l}41.91 \\
7249\end{array}$ & $\begin{array}{l}51267 \\
\text { (54.31) }\end{array}$ & $\begin{array}{l}51325 \\
4524]\end{array}$ \\
\hline Dier & $\begin{array}{l}53.44 \\
[5] .61]\end{array}$ & $\begin{array}{l}54572 \\
57.001\end{array}$ & $\begin{array}{l}556.21 \\
\text { [6275] }\end{array}$ & $\begin{array}{l}56978 \\
\text { (59.31) }\end{array}$ & $\begin{array}{l}503 B 2 \\
415 T]\end{array}$ \\
\hline \multicolumn{6}{|l|}{ Ifft tand } \\
\hline Young & $\begin{array}{l}428.45 \\
\text { [525] }\end{array}$ & $\begin{array}{l}45 \times 53 \\
{[5.56]}\end{array}$ & $\begin{array}{l}40.15 \\
49.50)\end{array}$ & $\begin{array}{l}\text { 485.51 } \\
\text { (4285) }\end{array}$ & $\begin{array}{l}\text { 96.42 } \\
\text { [DDS] }\end{array}$ \\
\hline Dider & $\begin{array}{l}5683 \\
{[5177]}\end{array}$ & $\begin{array}{l}505.70 \\
47.00]\end{array}$ & $\begin{array}{l}590.88 \\
4834\end{array}$ & 62867 & $\begin{array}{l}\text { (2400 } \\
\text { (35.7) }\end{array}$ \\
\hline
\end{tabular}




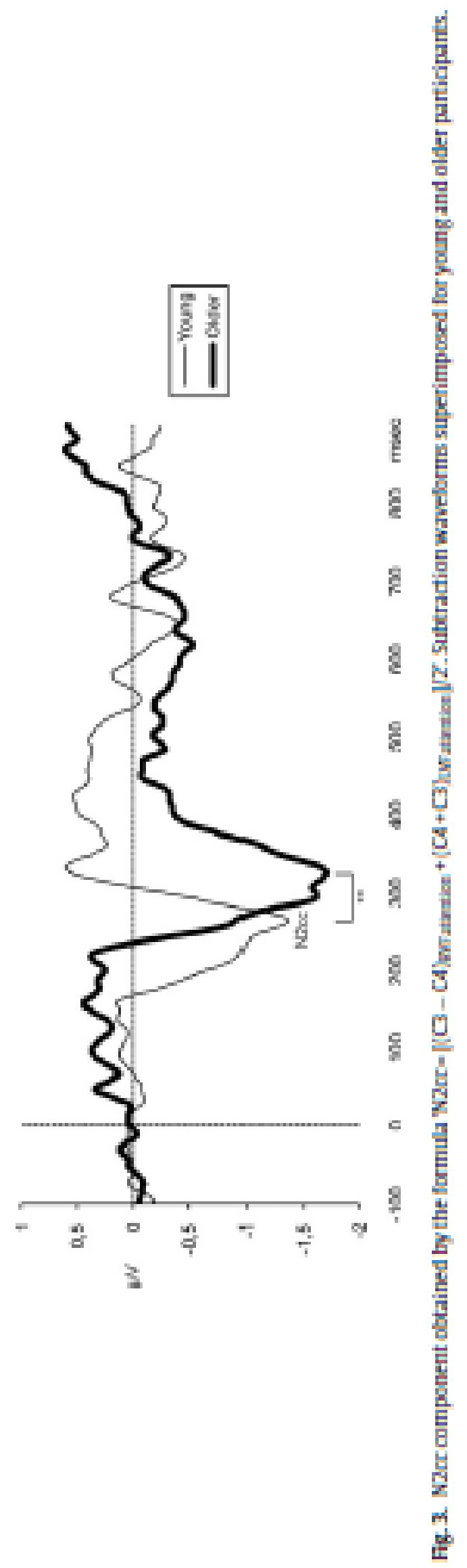

Post-print (final draft post-refereeing) 


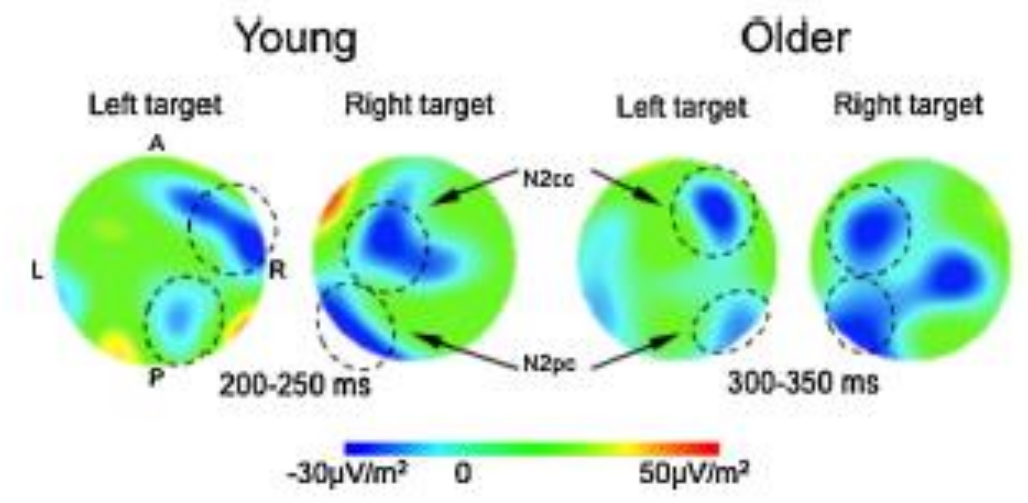

Fig. 4. Curnent source detsity maps (spherical spline interpolation, Perrin et at, 1980). The maps show central and postericr negative maxima corresponding to N2er and Napc components in each age group (highligted with dashed black orcles). A: anterior; P. posterior: L: ift: R: right.

Table 2

Mean values (standard deviation) of N2pC and N2cr components across age groups.

\begin{tabular}{|c|c|c|c|c|c|c|}
\hline & \multicolumn{2}{|c|}{ N2pc P03-P04 (right target) } & \multicolumn{2}{|c|}{ N2pc PD4-PO3 (ieft target) } & \multicolumn{2}{|l|}{$\mathrm{N} 2 \mathrm{ar}$} \\
\hline & Young & Obder & Young & Dlder & Young & Dlder \\
\hline Peak latency (ms) & 248.31 (15.08) & $304.12(35.11)$ & $235.31(25.14)$ & $302.12(30.42)$ & $247.00(25.74)$ & $317.18(42.27)$ \\
\hline Peak amplitude $(\mu \mathrm{V})$ & $-4.45(3.87)$ & $-3.10(1.74)$ & $-3.97(3.2)$ & $-2.58(1.96)$ & $-1.05(1.05)$ & $-1.72(1.22)$ \\
\hline Mean amplitude (uV) & $-1.40(2.75)$ & $-0.79(1.33)$ & $-1.93(259)$ & $-1.31(1.36)$ & -0.90 (0.6ग) & $-0.98(0.80)$ \\
\hline
\end{tabular}


Table 3

Mean amplitude and latency values (standard devation) of $\mathrm{kP}$ components at the cortralateral electrode (CO for rigte hand: $\mathrm{C4}$ for left hand) across assigred response hand in each age group.

\begin{tabular}{|c|c|c|c|c|c|}
\hline Hand & Age group & RP component & & Compatible target & Incompatible targes \\
\hline \multirow[t]{12}{*}{ Righte } & \multirow[t]{6}{*}{ Young } & \multirow[t]{4}{*}{ MP } & Peak amplizude $(\mu v)$ & $-5.21(2.87)$ & $-3.55(3.00)$ \\
\hline & & & Peak latency (ms) & $-267.14(6.43)$ & $-28 \pi / 43(115.107)$ \\
\hline & & & Onset latency (ms) & $-293.71(44.96)$ & $-419.43(84.41)$ \\
\hline & & & Rise time (ms) & 55.14 (75.35) & 132.00 (57.60) \\
\hline & & \multirow[t]{2}{*}{$\mathbb{R A P}$} & Peak amplizude $(\mu \mathrm{V})$ & $19.18(7.23)$ & $14.22(8.79)$ \\
\hline & & & Peak latency (ms) & $-57.14(32.22)$ & $-50.57(45.40)$ \\
\hline & \multirow[t]{6}{*}{ older } & \multirow[t]{4}{*}{ MP } & Peak amplizude $(\mu \mathrm{V})$ & $-11.53(5.34)$ & $-7.21(5.39)$ \\
\hline & & & Peak latency (ms) & -251.78 (65.98) & $-310.89(112.15)$ \\
\hline & & & Onset latency (ms) & -380.11 (120.96) & $-502.00(76.80)$ \\
\hline & & & Rase time (ms) & $127.34(87.77)$ & 211.12 (9658) \\
\hline & & \multirow[t]{2}{*}{ RAP } & Peak amplizude $(\mu \mathrm{V})$ & 6.44 (7.63) & $5.82(7.03)$ \\
\hline & & & Peak latency (ms) & $-88.23(37.67)$ & $-75.12(43.95)$ \\
\hline \multirow[t]{12}{*}{ Left } & \multirow[t]{6}{*}{ Young } & \multirow[t]{4}{*}{ MP } & Peak amplizude $(\mu \mathrm{V})$ & $-8.32(1.91)$ & $-7.62(3.60)$ \\
\hline & & & Peal latency (ms) & $-251.34(85.50)$ & $-221.67(54.62)$ \\
\hline & & & Onset latency (ms) & $-275.00(93.37)$ & $-39 \pi 34(53.49)$ \\
\hline & & & Rise time (ms) & $13.67(2.07)$ & $166.67(62.49)$ \\
\hline & & \multirow[t]{2}{*}{ RAP } & Peak amplizude $(\mu \mathrm{V})$ & $18.51(7.41)$ & $1200(15.65)$ \\
\hline & & & Peak latency (ms) & $-38.00(28.40)$ & $-Z 150(20.62)$ \\
\hline & \multirow[t]{6}{*}{ alder } & \multirow[t]{4}{*}{ MP } & Peak amplíude $(\mu \mathrm{V})$ & $-10.32(5.85)$ & $-8.50(5.05)$ \\
\hline & & & Peak latency (ms) & $-220.00(128.84)$ & $-236.50(27.79)$ \\
\hline & & & Onset latency (ms) & $-337.75(41.06)$ & $-530.50(104.80)$ \\
\hline & & & Rise time (ms) & $117.75(120.93)$ & 286.75 (96.7I) \\
\hline & & \multirow{2}{*}{ RAP } & Prak amplizude ( $\mu \mathrm{V})$ & $2.92(5.59)$ & $3.47(5.93)$ \\
\hline & & & Peak latency (ms) & -37.75 (53.65) & -100.50 (54.48) \\
\hline
\end{tabular}

Table 4

Partial correlation values between behwioural and electrophysiological measures with agr as control variable.

\begin{tabular}{|c|c|c|c|c|c|c|c|}
\hline & $\begin{array}{l}\text { N2oc latency } \\
\text { (ms) }\end{array}$ & $\begin{array}{l}\text { N2cecpeak } \\
\text { amplitude }(\mu V)\end{array}$ & $\begin{array}{l}\text { N2ce mean } \\
\text { amplitude }(\mu V)\end{array}$ & $\begin{array}{l}\text { MP peak } \\
\text { amplitude }(\mu V)\end{array}$ & $\begin{array}{l}\text { MPpeak } \\
\text { latency (ms) }\end{array}$ & $\begin{array}{l}\text { MP rise } \\
\text { time (ms) }\end{array}$ & $\begin{array}{l}\text { RAP peak } \\
\text { latency (ms) }\end{array}$ \\
\hline $\begin{array}{l}\text { IRT (ms) } \\
\text { Hit rate (B) }\end{array}$ & $0.36^{\circ}$ & $0.49^{\prime}$ & $-0.55^{-}$ & $0.3 \pi^{\prime}$ & -0.57 & $-0.44^{\circ}$ & $-078 \overrightarrow{7}$ \\
\hline
\end{tabular}

p $<01$ (27) two-tailed depres of freedom).

- p<.001 [Z] two-tailed degrees of freedom].

- p< 0001 (27) two-tailed deyees of freedom). 

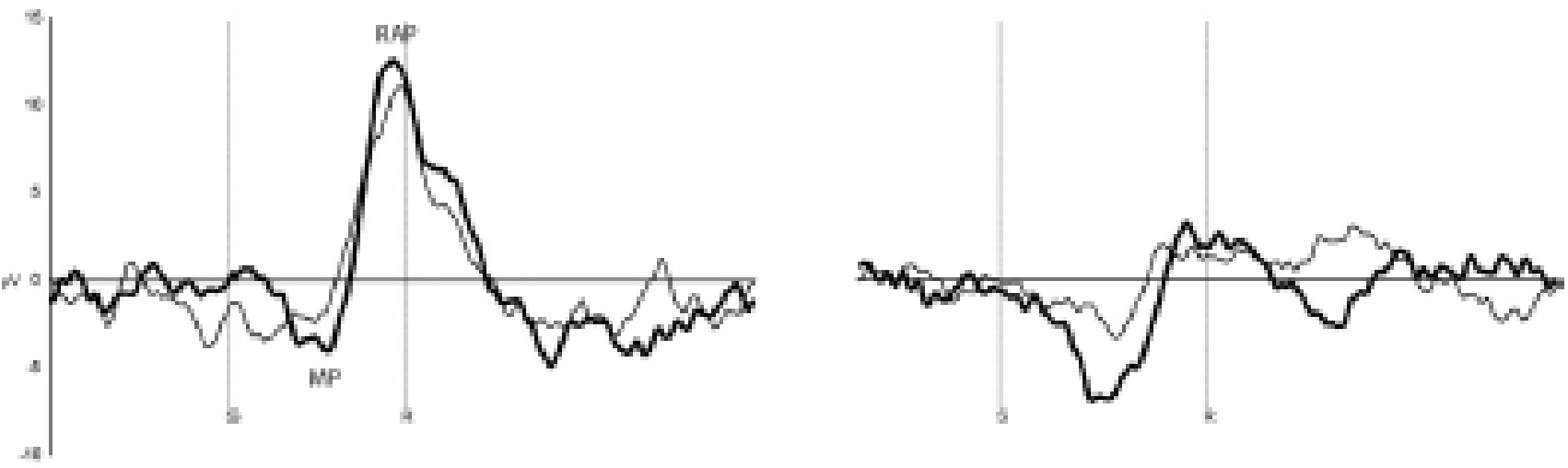

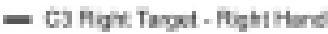

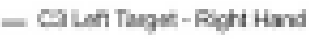
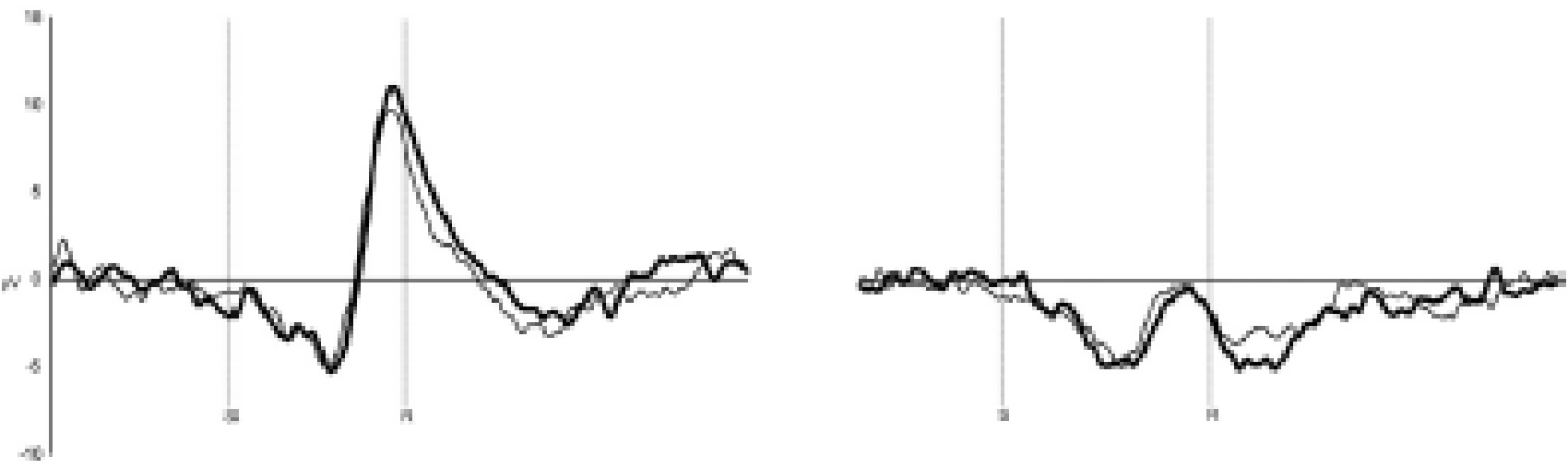

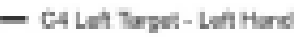

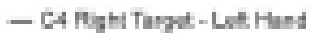
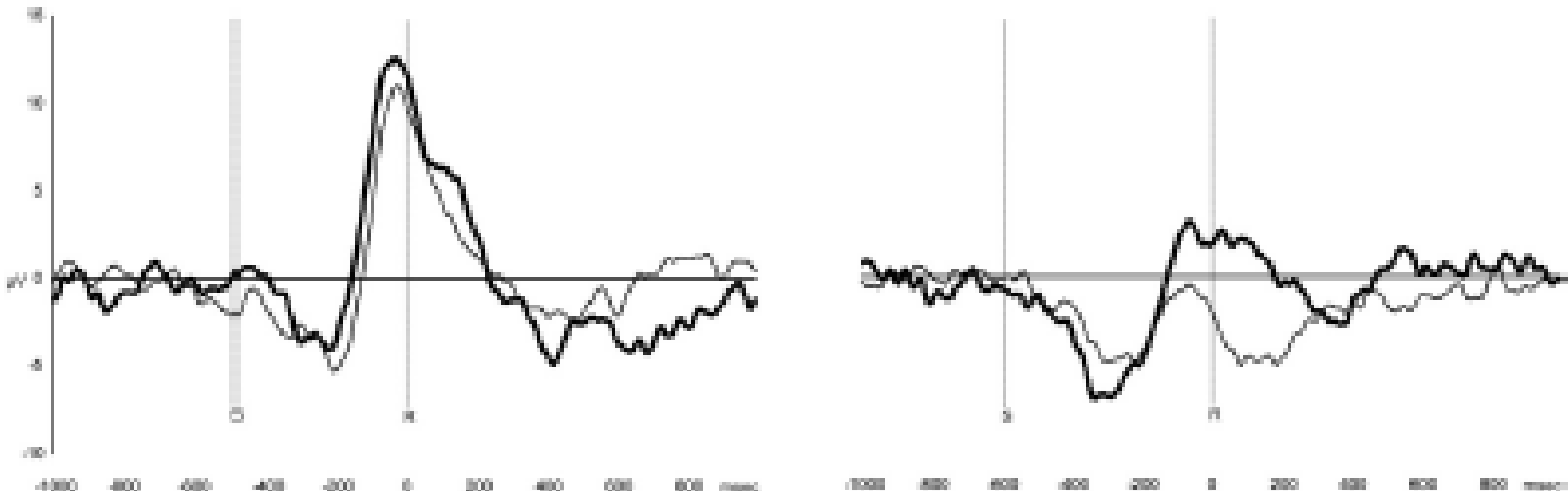

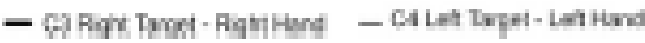

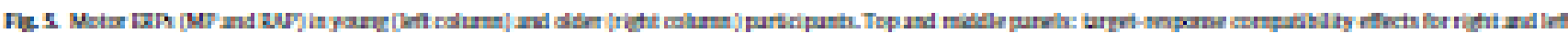

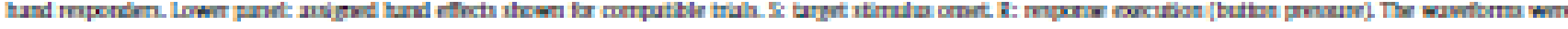

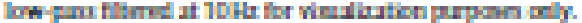

